\title{
AN ELECTRON MICROSCOPIC STUDY OF A CASE OF DERMATOMYOSITIS
}

\author{
BY \\ W. COCHRANE AND D. V. DAVIES \\ Arthritis and Rheumatism Council's Electron-microscopy Unit, \\ St. Thomas's Hospital Medical School, London
}

The clinical aspects of this and other cases of dermatomyositis are discussed by Ansell, Hamilton, and Bywaters (1965) and a histological and chemical examination of the tissue was reported by Loewi and Dorling (1964). Since the disease is uncommon and electron microscopical studies have not yet been reported, the findings from a single case are worthy of record.

\section{Materials and Methods}

The material was a biopsy specimen of a calcified deposit from the thigh muscles of a male patient aged 18 years. A small piece (of $1 \mathrm{~mm}$. dimension) at the edge of the calcified mass was fixed in 1 per cent. osmium

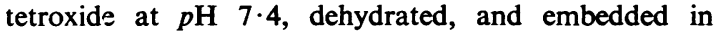
"Araldite". The remainder of the specimen was fixed in formalin and embedded in paraffin. The usual $8 \mu$ sections for light microscopy, stained with haematoxylin and eosin, were obtained from the paraffin block. Also for light microscopy, $1 \mu$ sections were cut with a glass knife from the Araldite block; these were stained with azure II-methylene blue (Richardson, Jarett, and Finke, 1960). For electron microscopy, a Leitz ultramicrotome with a diamond knife was used to cut ultrathin sections. These were picked up on uncoated copper grids and stained for one hour in a saturated solution of uranyl acetate in methanol. The thin sections were examined in an A.E.I. E.M. 6 electron microscope working at 75 kilovolts. A few thin sections were stained with 0.25 per cent. phosphotungstic acid for 16 hours.

\section{Results}

Light Microscopy.-The $1 \mu$ and $8 \mu$ sections showed tracts of relatively acellular dense white connective tissue interspersed with areas of calcification of variable size. Some of the larger calcified masses had fallen out or been displaced during the preparation (Fig. 1).

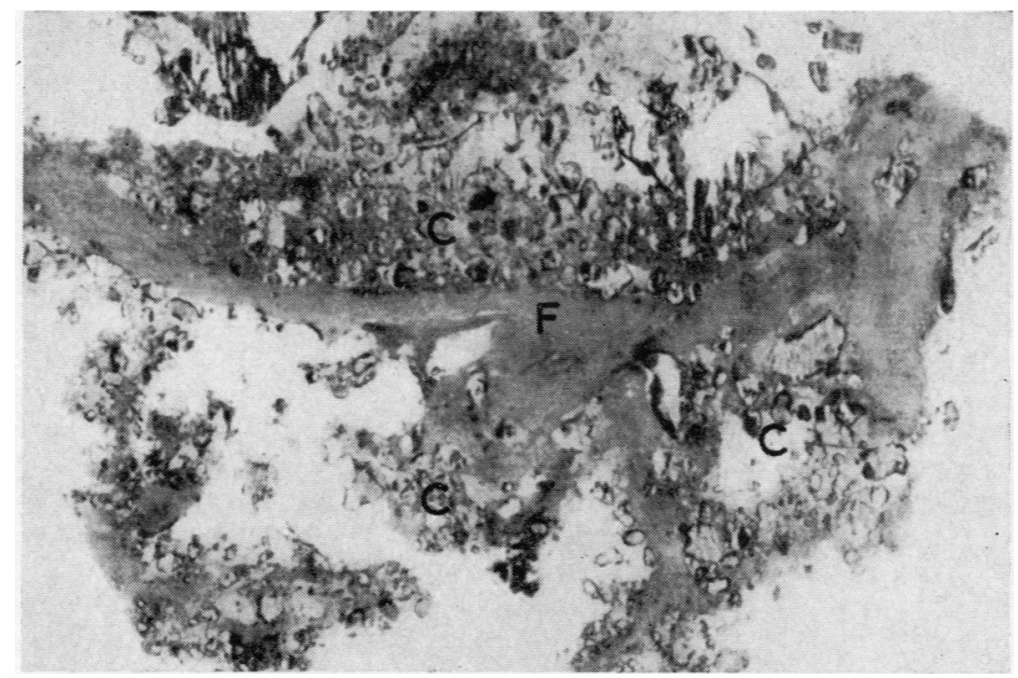

Fig. 1. - Thin $(1 \mu)$ section of a calcified area and its surround. Azure II-methylene blue. $\quad$ C $=$ Calcification. $\quad F=$ Collagen. $\quad \times 190$. 


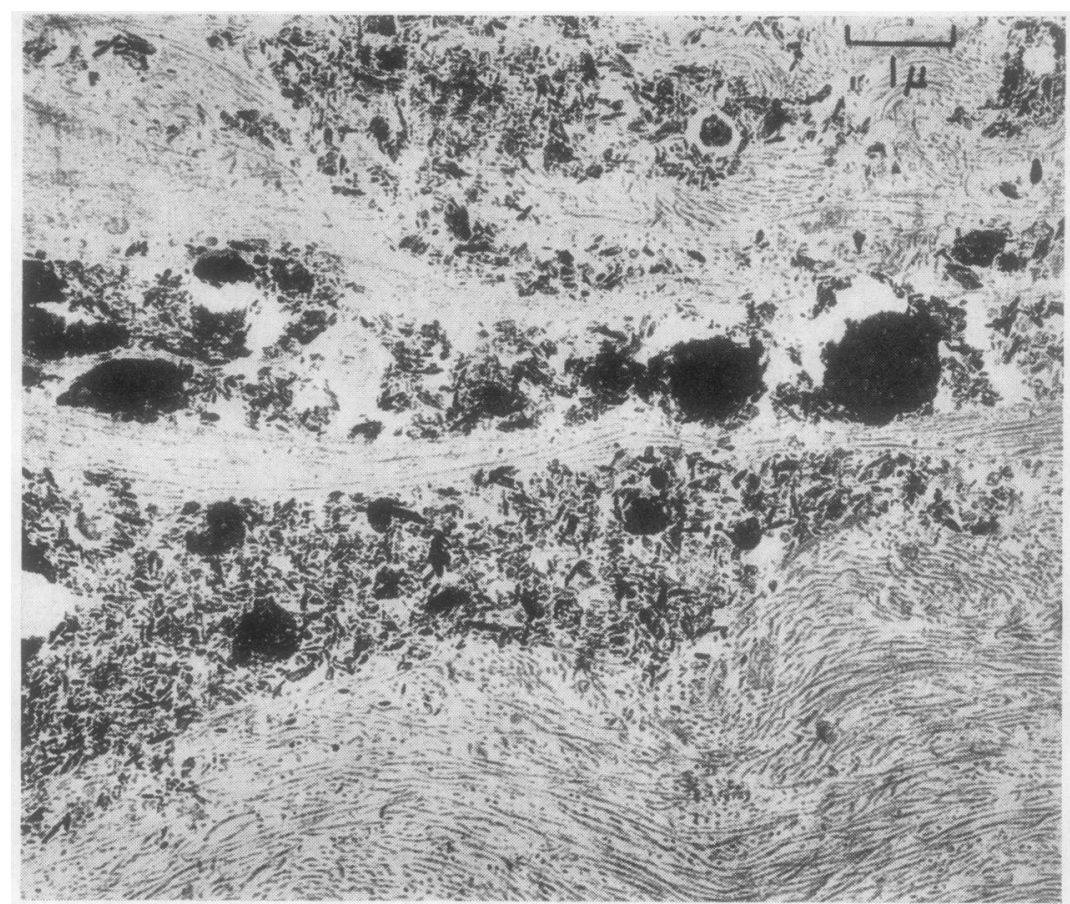

Fig. 2.-Low-power electron micrograph, showing bundles of collagen fibrils running in various directions and interspersed with areas of calcification. Stained with uranyl acetate. $\times 11,700$.

Electron microscopy.-At low magnification (Fig. 2) the electron micrographs confirmed the light microscope findings. The connective tissue consisted of collagen fibrils, usually arranged in bundles running in various directions. Only one micrograph showed material which might be identified as elastin. No muscle fibres were seen and no fat was present.

At higher magnifications $(\times 50,000)$ the following components, which will be considered separately, were identifiable: collagen fibrils, an interfibrillar filamentous material, and calcified deposits and cells.

The collagen fibrils were usually collected into bundles which ran in various directions and often intermingled. The spacing between fibrils varied; collectively they occupied from 10 to 30 per cent. of the sectional area. The individual fibrils varied from 300 to $500 \AA$ in diameter. They were thus relatively thin as compared with those in other mature connective tissues such as cartilage or tendon. Many fibrils were bent, sometimes acutely (Fig. 3, opposite).
When stained with uranyl acetate the fibrils showed a cross-banding at about $90 \AA$ between the centres of the dark bands. This spacing was not absolutely uniform and the electron-dense bands were generally grouped in pairs (Fig. 4, opposite).

With phosphotungstic acid staining there were signs of the $640 \AA$ cross-banding on a few thick fibrils.

Fine filaments were present amongst the collagen fibrils in about half the micrographs. Many were branched and bent, often acutely. These filaments were about $20 \AA$ in diameter and thus close to the limits of resolution of the microscope. They were beaded at irregular intervals of about $100 \AA$ (Fig. 5, opposite).

The calcified deposits varied in size, the largest measuring up to $3 \mu$ in diameter; between the larger deposits the connective tissue was peppered with smaller calcified masses. The centres of the larger masses were nearly opaque to $75 \mathrm{kV}$ electrons. At the edges of such masses and in the smaller calcified areas, the material was less opaque and its finer structure was visible. Several forms of calcification could be recognized. 


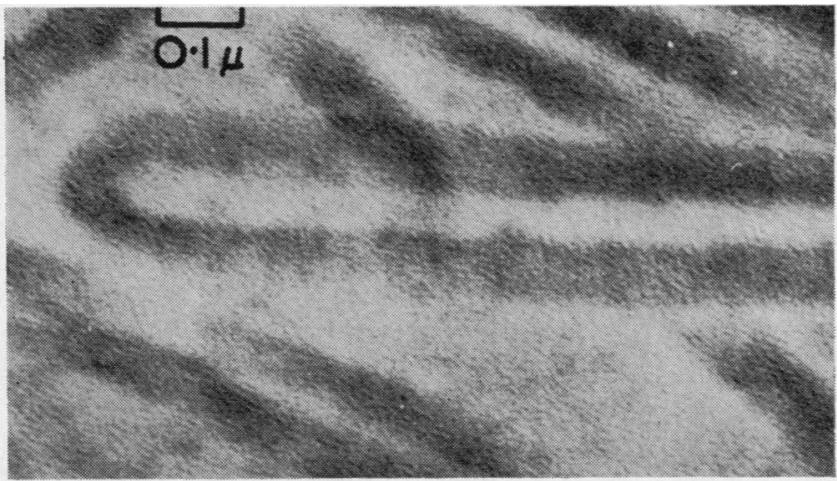

Fig. 3.-A collagen fibril, showing a sharp bend. The banding is indistinct. Stained with phosphotungstic acid. $\times 84,500$.

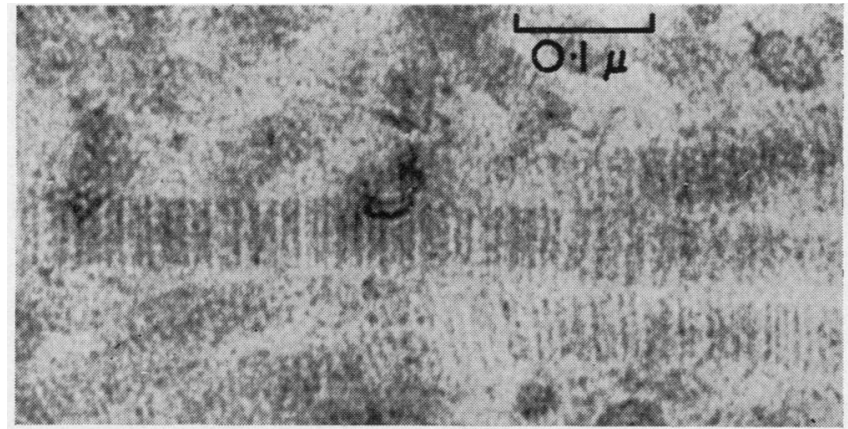

Fig. 4. - Collagen fibrils, showing cross-banding. Note that the dark bands are arranged in doublets. Stained with uranyl acetate. $\times 148,750$.

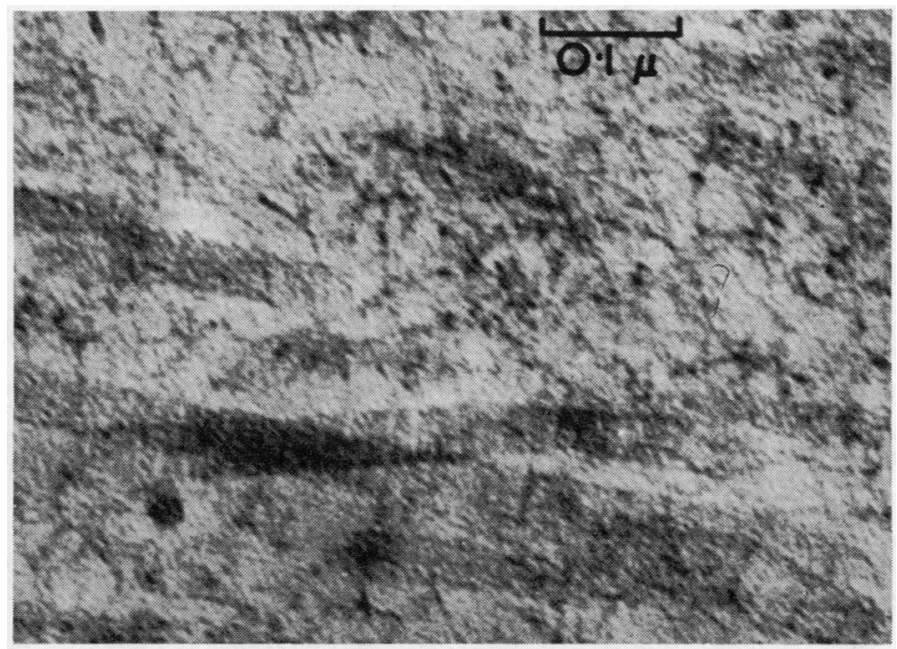

Fig. 5.-Electron micrograph showing an abundance of fine beaded filaments. Stained with uranyl acetate. $\times 148,750$. 
The commonest form was a plate or rod perforated with electron-translucent "holes" or tracts (Fig. 6). These "holes" were about $50 \AA$ in diameter and spaced at about $100 \AA$ between their centres, the whole giving a sieve-like or grid-like appearance. The "holes" were frequently disposed in regular rows along the length of the plate or rod. The rods and plates varied considerably in dimension-from a rod $2,000 \AA$ long and $300 \AA$ wide to a plate of rhomboid or trapezoid shape a few thousand ångstroms in dimension.

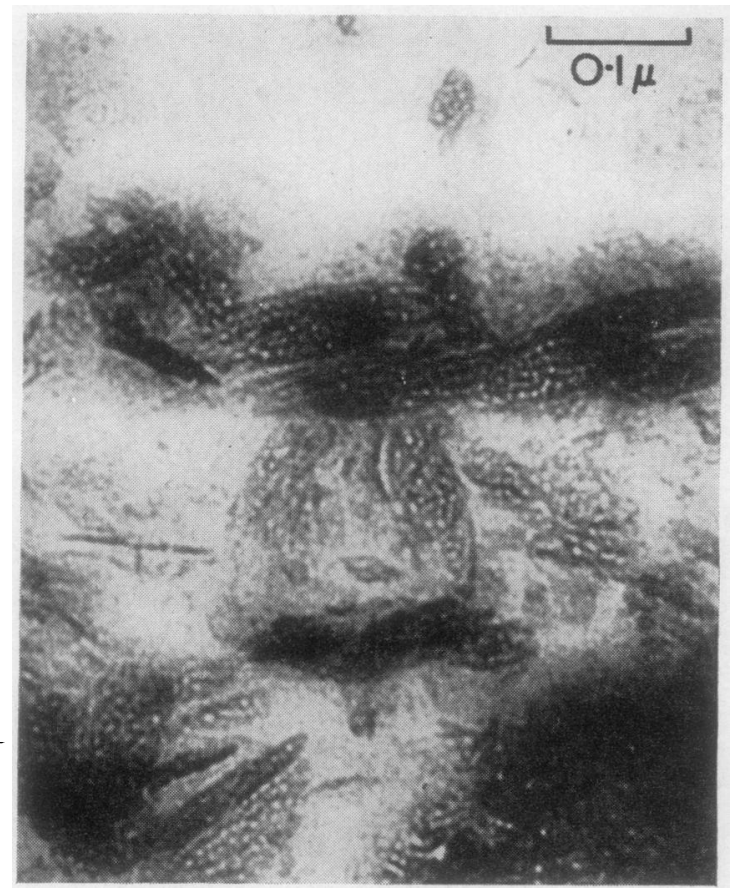

Fig. 6.-Plate-like calcifications at the edge of a denser mass. Note their sieve-like structure. Stained with uranyl acetate. $\times 148,750$.

Diffractograms, from areas $6,000 \AA$ in diameter, showed a ring pattern typical of apatite with a particularly strong ring corresponding to a Bragg spacing of $2 \cdot 7 \AA$. The rings were spotty, indicating large crystal grain size (Fig. 7).

A less frequent form of calcification consisted of a tangled mass of uniformly electron-dense threads (Fig. 8, opposite), about 1,000 to $2,500 \AA$ in length and $50 \AA$ thick. They were often wavy or bent. They formed dense masses around the periphery of which there were smaller groups and individual threads. Diffractograms from an area $6,000 \AA$ in diameter showed rings due to apatite and

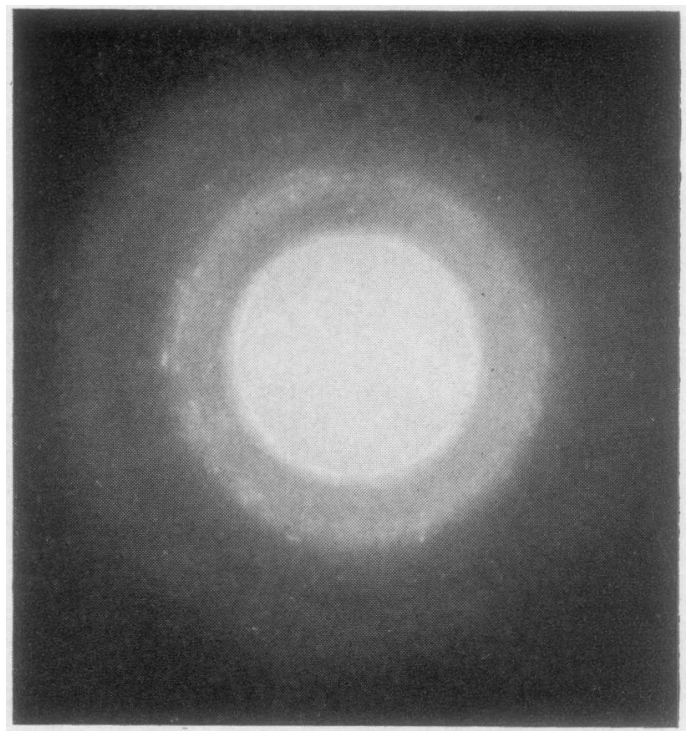

Fig. 7.-Diffraction pattern from a mass of plates, showing spotty rings characteristic of apatite.

a large crystal grain size. It was not possible to obtain a pattern from a single thread, owing to its small size; the haloes characteristic of Araldite masked the apatite pattern.

In other areas the calcified material consisted of scattered spindle-shaped bodies (Fig. 9, opposite), with "holes" or "cavities" along their long axes. Occasionally the interior of the spindle was completely electron-translucent. Selected area diffraction from a single spindle gave a spot pattern, indicating that it was effectively a single crystal of apatite with its ' $c$ ' axis along its length.

Occasional areas of calcifications consisted of fine granules and threads (Fig. 10, opposite) near the limit of resolution of the microscope (10-20 $\AA)$. Diffraction from an area of diameter $6,000 \AA$ indicated small crystal grains of apatite.

Many instances were seen where calcification was apparently taking place on collagen fibrils (Fig. 11, opposite).

The calcified material was particulate and near the limit of resolution. It was so disposed as to give a banding effect on the fibres. Diffraction was difficult owing to confusion with the Araldite haloes, but the $2.7 \AA$ apatite ring was detected. It was broad indicating small crystal grain size.

Only two very degenerate cells were seen; roughwalled endoplasmic reticulum and vacuoles could be identified within them. 
Fig. 8.-Calcification in the form of a tangled mass of electron-dense threads. Stained with uranyl acetate. $\times \quad 148,750$
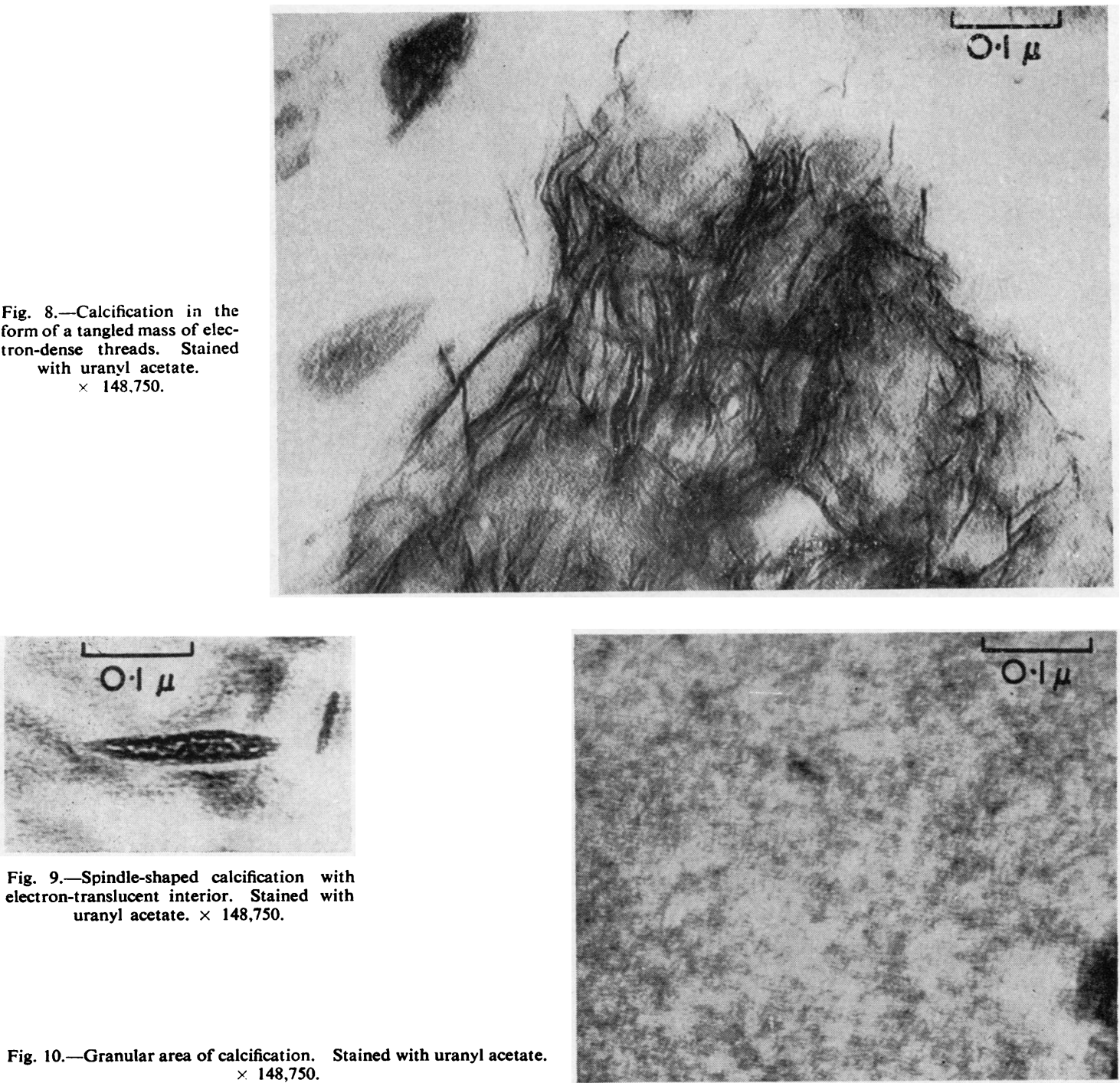

Fig. 9.-Spindle-shaped calcification with electron-translucent interior. Stained with uranyl acetate. $\times 148,750$.

Fig. 10.-Granular area of calcification. Stained with uranyl acetate. $\times 148,750$.

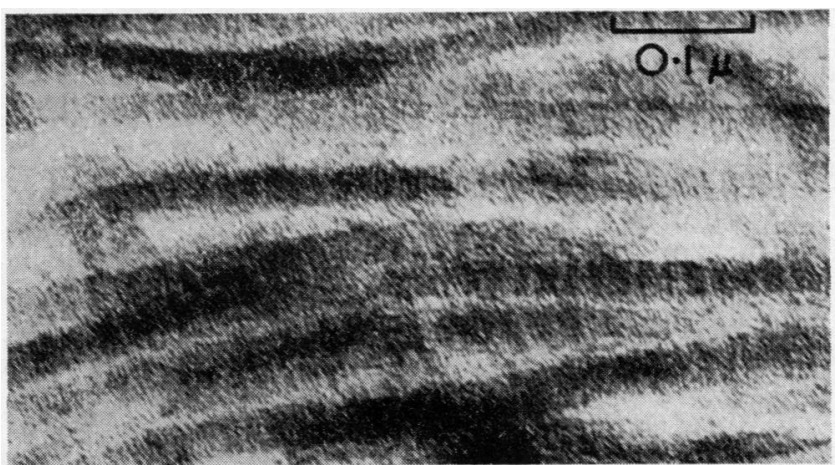

Fig. 11.-Calcification on a collagen fibril; note banding. Stained with uranyl acetate. $\times 148,750$. 


\section{Discussion}

The electron micrographs emphasize the dominance of collagen as the main organic matrix. The filamentous interfibrillar material may be a fixation artefact of proteinous fluid in the original specimen. Judged by their somewhat small diameter and the general absence of a clear $640 \AA$ banding, the majority of the collagen fibrils are immature.

Calcification appears to begin by the deposition of very small apatite particles in and on the collagen fibrils. The grains unite, leaving uncalcified areas which may contain organic matrix and which give the sieve-like structure of the plates and rods and the axial electron-translucent interior of the spindles. In other cases the grains grow either by accretion or possibly by fusion to form threads. Alternatively, the granular nature of the calcification persists, but loses the original regularity.

The electron diffractograms from a calcified area of $6,000 \AA$ diameter indicate large crystal grains, and diffraction from a small element gives a single crystal pattern. Such a single crystal does not necessarily signify one solid mass; it may consist of an aggregate of small particles with the same crystal lattice running through them. Thus the indication is that groups of the very small apatite particles originally deposited may grow and unite with the same orientation without any discontinuity of the crystalline structure at the joints. This method of growth may be difficult to achieve, since the initial particles may not be appropriately orientated or spaced. Assuming that the initial particles are based on collagen fibrils, it seems likely that considerable strains may be created during such union. The collagen fibrils are likely to be distorted and damaged in the early stages and may finally lose their identity.

\section{Summary}

Biopsy material from a case of dermatomyositis is examined. The calcified masses are adjacent to regions showing collagen fibrils, many of which are immature. The fibrils are sometimes considerably bent. The calcified material is identified, by electron diffraction, as apatite and its appearance is described. It is deduced that calcification consists mainly of a build-up of apatite in and on the collagen fibrils.

The authors are much indebted to the Arthritis and Rheumatism Council for the facilities provided by their Electron Microscopy Unit. Thanks are due also to Prof. E. G. L. Bywaters for the provision of the material and to Messrs. J. S. Fenton, W. C. Harding, and G. Maxwell for technical assistance.

\section{REFERENCES}

Ansell, B. M., Hamilton, E. B. D., and Bywaters, E. G. L. (1965). Ann. rheum. Dis., 24, in press.

Loewi, G., and Dorling, J. (1964). Ibid., 23, 272.

Richardson, K. C., Jarett, L., and Finke, E. H. (1960). Stain Tech., 35, 313.

\section{Étude au microscope électronique d'un cas de dermatomyosite \\ RÉSUMÉ}

On a examiné des prélèvements à la biopsie d'un cas de dermatomyosite. Les masses calcifiées sont adjacentes aux régions montrant des fibrilles collagènes dont beaucoup sont immatures. Quelquefois ces fibrilles sont considérablement recourbées. On identifie le matériel calcifié par diffraction électronique comme apatite et on en décrit l'apparence. On conclut que la calcification consiste surtout en un édifice d'apatite dans et sur des fibrilles collagènes.

\section{Estudio electron-microscopico de un caso de dermatomiositis}

SUMARIO

Se examinó el material de biopsia de un caso de dermatomiositis. Las masas calcificadas fueron adyacentes a regiones con fibrillas colágenas, muchas de ellas inmaduras. A veces estas fibrillas eran considerablemente encorvadas. El material calcificado fué identificado por difracción electrónica como apatita; su apariencia se describe. Se deduce que la calcificación consiste de un edificio de apatita dentro y sobre fibrillas colágenas. 